\title{
A Case of Unexpected Clinostomum complanatum Infection Initially Presenting as Foreign Body in Pharynx
}

\author{
Hyunjung Kim¹, Sung-Weon $\mathrm{Cho}^{2}$, Harim $\mathrm{Oh}^{3}$, Hyung Kwon Byeon,** \\ 'Department of Otorhinolaryngology-Head and Neck Surgery, Korea University College of Medicine, Seoul 02841, Korea; ${ }^{2}$ Department of \\ Parasitology, Korea University College of Medicine, Seoul 02841, Korea; ' 3 Department of Pathology, Korea University College of Medicine, Seoul \\ 02841, Korea; ${ }^{4}$ Department of Otorhinolaryngology-Head and Neck Surgery, Soonchunhyang University College of Medicine, Seoul 04401, Korea
}

\begin{abstract}
A 46-year old man visited our outpatient clinic with complaint of foreign body sensation in throat after consuming raw freshwater fish 5 days ago. Laryngoscopic examination revealed a motile worm attached on posterior pharyngeal wall. The worm was removed using biopsy forceps under transnasal endoscopy and evidently identified as Clinostomum complanatum after microscopic examination. Patient's subjective foreign body sensation of throat and hyperemia of laryngeal mucosa remained for approximately 2 weeks post-removal, which were eventually resolved after administration of non-steroidal anti-inflammatory drug and anti-refluxant drug for 2 weeks. Treatment was ended at three weeks since the first visit. C. complanatum infections in humans are rare, and only four cases have been reported in Korea. Symptoms resembling pharyngitis or laryngitis occurs by consumption of raw, infected freshwater fish and treatment is done by mechanically removing the parasite.
\end{abstract}

Key words: Clinostomum complanatum, human case, raw freshwater fish, laryngopharyngitis

\section{INTRODUCTION}

Clinostomum complanatum, also commonly known as "yellow grub" is a digenetic trematode. The eggs of these flatworms are released into the water from beaks and throats of definitive hosts such as herons which then infect freshwater fish [1]. Consumption of raw freshwater fish such as mullet or perch by humans can cause laryngeal or pharyngeal infections, though the incidence is very rare. Since its first report in 1995, only 4 cases have been reported until date in Korea. In the previous reports, patients visited the clinic with sore throat symptoms which developed as early as 3 days after consuming freshwater fish and endoscopic examination evidently revealed parasitic infections at various sites such as pharynx, larynx, and nasopharynx [2]. The flatworms were endoscopically or surgically removed under sedation and symptoms were eventually resolved.

\footnotetext{
- Received 18 January 2019, revised 19 March 2019, accepted 20 March 2019.

*Corresponding author (ewellcastle@gmail.com)

(C) 2019, Korean Society for Parasitology and Tropical Medicine

This is an Open Access article distributed under the terms of the Creative Commons Attribution Non-Commercial License (http://creativecommons.org/licenses/by-nc/4.0) which permits unrestricted non-commercial use, distribution, and reproduction in any medium, provided the original work is properly cited.
}

\section{CASE RECORD}

A 46-year old man with no underlying disease was referred to our ENT department from a local clinic for removal of what appeared to be a foreign body (black thread) in pharynx. The patient presented with complaints of foreign body sensation in his throat for the past 2 days and had a history of raw freshwater fish consumption 5 days ago. Close examination under laryngoscopy revealed an approximately $1 \mathrm{~cm}$-sized spontaneously moving organic material located on the posterior pharyngeal wall, just posterior to the interarytenoid mucosa (Fig. 1). The organism was grasped with biopsy forceps under transnasal flexible endoscopy, in which it was cut into 2 pieces during the process; the obtained specimen was sent for pathologic examination and the remnant piece was suctioned and was unable to be retrieved. Pathologic examination with parasitological consultation identified the organism as an adult parasite worm, C. complanatum (Fig. 2). The retrieved portion of the parasite was prepared and stained with hematoxylin and eosin. Morphological examination of the incomplete piece of C. complanatum under light microscopy measured $0.95 \mathrm{~mm}$ in length and $0.45 \mathrm{~mm}$ in width. The oral sucker which was located anteriorly, measured $0.1 \mathrm{~mm}$ long and wide, and the ventral sucker, which was located approximately $0.2 \mathrm{~mm}$ cau- 


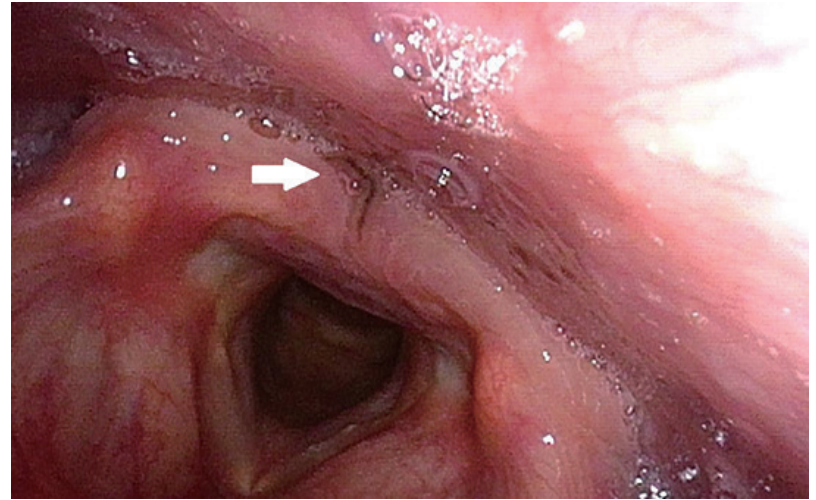

Fig. 1. Motile organism is attached to posterior pharyngeal wall, just posterior to the interarytenoid mucosa (white arrow).

dal to the oral sucker, measured $0.3 \mathrm{~mm}$ long and wide. According to measurements from previous reports, the ventral sucker of C. complanatum is located in the anterior third of the body [3]. Considering these morphological characteristics, the total longitudinal length of this parasite could be assumed to be approximately $2.0 \mathrm{~mm}$ long. Intestinal caeca were observed bifurcated on both lateral sides of the parasite in symmetry. The portion of the parasite containing reproductive organs was unable to be retrieved. Considering these morphological characteristics and the anatomical site of infection, the parasite was diagnosed as C. complanatum. Follow up endoscopy 1 week after the procedure revealed mild hyperemia of the treated site of mucosa which was completely recovered by the second week. Conservative medical treatment with nonsteroidal antiinflammatory drug and anti-refluxant drug was provided for 2 weeks, and the foreign body sensation was completely resolved by the last follow-up visit.

\section{DISCUSSION}

C. complanatum is a digenetic trematode that naturally parasitizes in the throat of piscivorous birds such as herons and egrets, and many species of fresh-water fish are recorded as second intermediate hosts [3]. Fish-borne trematode infections in humans result from eating raw or undercooked freshwater fish [4]. Although the general incidence of human parasitic infection is decreasing due to changes in lifestyle and use of chemical fertilizers, infections of food-borne parasites are still observed in areas where people remain to consume raw meat of fish [5]. Human C. complanatum infection was first reported by Yamashita in 1938 in Japan, and the first case in Ko-

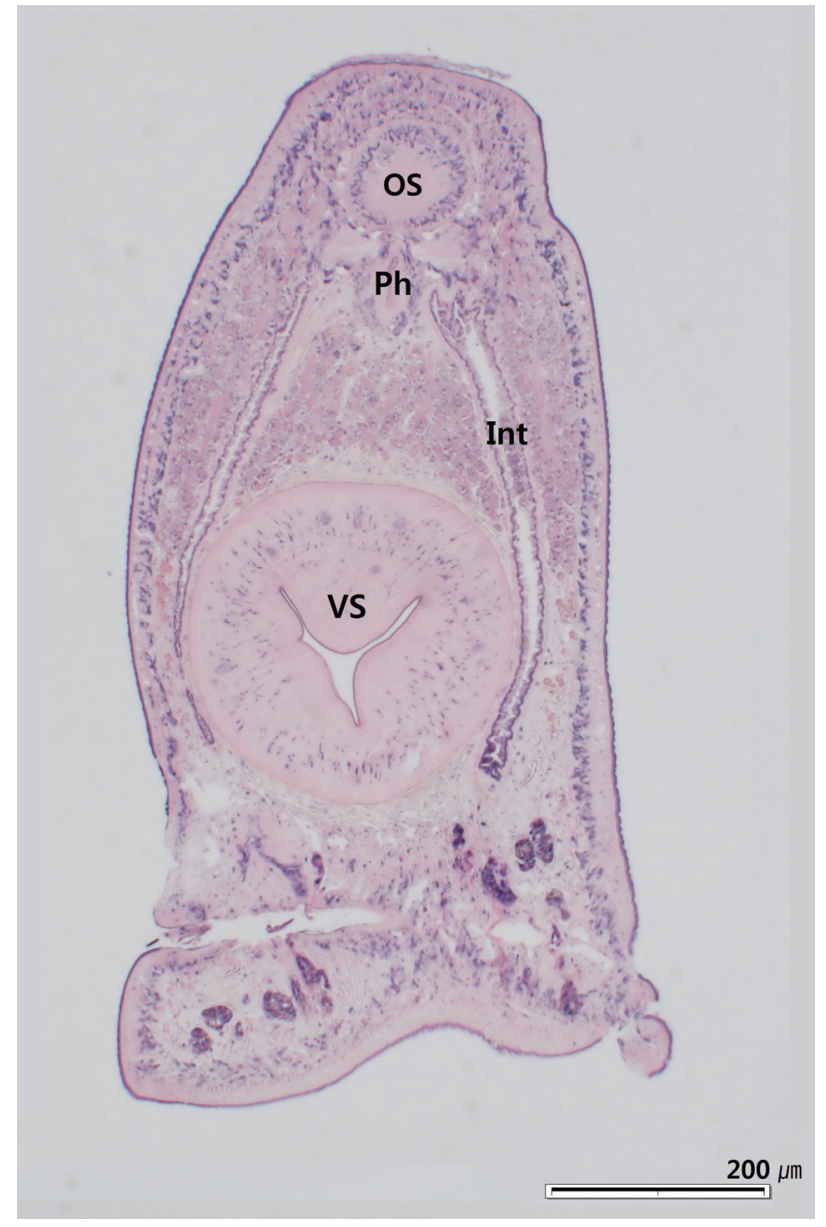

Fig. 2. Histological section of head portion of $C$. complanatum in $\mathrm{H} \& E$ stain showing oral sucker (OS), pharynx (Ph), intestinal caeca (Int), and ventral sucker (VS).

rea was reported by Chung in 1995 .

Usually the only symptom is throat discomfort, which occurs several days after consumption of infected fish. This is due to the life cycle of $C$. complanatum; when the metacercaria enters the human body, it excysts in the stomach and migrates through the esophagus and attaches to the throat where it matures [5]. The nutritional source of C. complanatum is glucose obtained from necrosis of engulfed tissues by the parasite's oral suckers [6]. Throat discomfort and petechial hemorrhage of the infected mucosa are usually self-limiting once the parasite is removed.

Infection is diagnosed by laryngoscopic or endoscopic examination, in which the parasite is spotted in various locations such as pharynx, arytenoid, or posterior pharyngeal wall [5]. To treat the infection, the flatworm is mechanically removed either under local or general anesthesia. Spraying of $8 \%$ 
lidocaine solution can be helpful in inhibiting its motility and eliminating suction to host's mucosa to safely remove the infection source without damaging surrounding tissues [7]. Antiparasitic medication is ineffective and upper gastrointestinal endoscopy is recommended to confirm that there is no other residual parasite $[2,5]$.

Previous cases reported C. complanatum infection in various sites such as posterior pharyngeal wall, larynx, and nasopharynx. Except for 1 case of upper pharyngeal infection in which simple otolaryngological removal was able to be done, endoscopic or surgical removal of parasites located in the larynx or nasopharynx required sedation or general anesthesia [2]. In the present case, transnasal flexible endoscopy was performed to remove the parasite in the larynx, which was performed in the outpatient clinic setting without any sedation or subsequent hospitalization. This office-based procedure allowed safe and complete removal of the foreign body, and was a convenient technique for both the clinician and the patient.

Laryngopharyngitis by C. complanatum infection is a rare occurrence and only a few cases have been reported in Korea. However, the incidence may have been underestimated due to inadequate endoscopic examination in the past. With increasing access to endoscopic examination, the number of reported cases are expected to grow with careful inspection and appropriate suspicion. In areas where rare freshwater fish meat consumption is still a common occurrence, $C$. complanatum infection should be considered as a possible diagnosis and endo- scopic examination and appropriate removal should be promptly done.

\section{CONFLICT OF INTEREST}

The authors declare no conflict of interest related to this study.

\section{REFERENCES}

1. Song HB, Choi MH, Chung EJ. Human laryngeal infection by Clinostomum complanatum. Am J Trop Med Hyg 2018; 98: 7-8.

2. Lee GS, Park SW, Kim J, Seo KS, You KW, Chung JH, Moon HC, Hong GY. A case of endoscopically treated laryngopharyngitis resulting from Clinostomum complanatum infection. Korean J Gastroenterol 2017; 69: 177-180.

3. Chung DI, Kong HH, Moon CH. Demonstration of the second intermediate hosts of Clinostomum complanatum in Korea. Korean J Parasitol 1995; 33: 305-312.

4. Sohn WM. Fish-borne zoonotic trematode metacercariae in the Republic of Korea. Korean J Parasitol 2009; 47 (suppl): 103-113.

5. Hara H, Miyauchi Y, Tahara S, Yamashita H. Human laryngitis caused by Clinostomum complanatum. Nagoya J Med Sci 2014; 76: 181-185.

6. Park CW, Kim JS, Joo HS, Kim J. A human case of Clinostomum complanatum infection in Korea. Korean J Parasitol 2009; 47: 401-404

7. Kitagawa N, Oda M, Totoki T, Washizaki S, Oda M, Kifune T. Lidocaine spray used to capture a live Clinostomum parasite causing human laryngitis. Am J Otolaryngol 2003; 24: 341-343. 
